Published in final edited form as:

Acad Radiol. 2019 April ; 26(4): 526-533. doi:10.1016/j.acra.2018.07.001.

\title{
Addressing Burnout in Radiologists
}

\author{
Alison L. Chetlen, D.O., \\ Penn State Health, Milton S. Hershey Medical Center, Department of Radiology, Division of \\ Breast Imaging 30 Hope Drive, Suite 1800 EC 008, Hershey PA 17033 \\ Tiffany L. Chan, M.D., \\ Penn State Health, Milton S. Hershey Medical Center, Department of Radiology, HO66, 500 \\ University Drive, PO Box 850, Hershey PA 17033
}

\section{David H. Ballard, M.D.,}

Mallinckrodt Institute of Radiology, Washington University School of Medicine, Campus Box 8131, 510 S Kings Highway Blvd, St. Louis, Missouri

\section{Alexandre Frigini, M.D.,}

Baylor College of Medicine, One Baylor Plaza 360, MD Anderson Hall, Suite 165-B, Houston, Texas 77030

\section{Andrea Hildebrand, M.D.,}

University of Vermont Medical Center, 111 Colchester Avenue, Burlington, VT 05401

\author{
Shannon Kim, M.D., \\ Eastern Virginia Medical School, Department of Radiology P.O. Box 1980, Norfolk, VA 23501
}

James M. Brian, M.D.,

Penn State Health, Milton S. Hershey Medical Center, Department of Radiology, Division of Pediatric Radiology, 500 University Drive, HO66, PO Box 850, Hershey PA 17033

Elizabeth A. Krupinski, PhD, FSIIM, FSPIE, FATA, FAIMBE, and Department of Radiology \& Imaging Sciences Emory University, 1364 Clifton Rd NE D107, Atlanta, GA 30322

\section{Dhakshinamoorthy Ganeshan, MD}

University of Texas MD Anderson Cancer Center, Department of Diagnostic Radiology, Pickens Academic Tower, 1400 Pressler Street, Unit 1473, Houston, TX 77030-4009

\section{Abstract}

Corresponding author: Alison L. Chetlen, D.O. Address: Penn State Health, Milton S. Hershey Medical Center, 30 Hope Drive, Suite 1800 EC 008, Hershey, PA 17033, Telephone: 717-531-1495, Fax: 717-531-4335, achetlen@ pennstatehealth.psu.edu.

Disclosures: None (All the authors confirm that there are no relevant disclosures)

Submission Declaration: All the authors confirm that this manuscript has not been published previously, and that it is not under consideration for publication elsewhere, that its publication is approved by all authors and tacitly or explicitly by the responsible authorities where the work was carried out, and that, if accepted, it will not be published elsewhere including electronically in the same form, in English or in any other language, without the written consent of the copyright-holder.

Compliance with ethical standards: All the authors confirm that this manuscript complies with ethical standards

Conflict of interest: All authors confirm that there are no relevant conflicts of interest. 
Burnout is a global health problem affecting physicians across all medical specialties. Radiologists, in particular, experience high rates of burn out, and this trend has only continued to worsen. The "Promoting Health and Wellness for Radiologists Task Force of the Association of University Radiologists - Radiology Research Alliance" presents a review of the prevalence, causes and impact of burnout among radiology faculty and trainees, and a discussion on strategies for overcoming burnout and promoting overall health and well-being among radiologists.

\section{Keywords}

Burnout; Physician Wellness; Radiologist Health and Wellbeing

\section{Introduction}

Burnout refers to a constellation of symptoms, including a loss of enthusiasm for work, a high degree of emotional exhaustion, high degree of depersonalization, and a low sense of personal accomplishment $(1,2)$. Physicians in the United States (US) are at a high risk of experiencing burnout symptoms compared to professionals in other fields $(1,2)$. More than $50 \%$ of US physicians report experiencing at least one symptom of burnout, and this trend has increased in recent years (1-3). Burnout is a global health problem affecting physicians across all medical specialties who work in variable hospital settings and work environments (1-8). Burnout is also prevalent among US physicians-in-training, including medical students, residents, and fellows (9-14). Such high levels of professional burnout among health care professionals have been shown to be detrimental to quality and safety in health care (15-19). Burnout can also lead to a loss in physician productivity, a decrease in professional effort, and may even lead to high physician turnover, early retirement contributing to worsening physician shortages, and increasing health care costs. Lastly, physician burnout has also been shown to significantly increase the risk of substance abuse and suicide among physicians (20-23).

The Association of University Radiologists Radiology Research Alliance Task Force on "Promoting Health and Wellness for Radiologists" convened to review the prevalence, causes, and impact of burnout among radiology faculty and trainees. We also discuss strategies for overcoming burnout and promoting overall health and well-being among radiologists at the individual and organizational levels.

\section{Background: Burnout in Radiologists}

Radiologists are experiencing high rates of burn out, and this trend has only become worse over the years. In 2014, Shanafelt et al. conducted a survey using the Maslach Burnout Inventory (MBI) to evaluate the prevalence of burnout among US physicians from various specialties, including radiologists (1). The MBI is a well-established and highly validated tool for measuring burnout on the basis of three key dimensions- emotional exhaustion, depersonalization and low personal accomplishment (24). Emotional exhaustion or fatigue has been described as feeling emotionally over-extended by work, while low personal accomplishment is essentially the feeling of reduced levels of competence and achievement at work. Depersonalization refers to treating patients and/or peers in an unfeeling way (25). 
Of the 6880 survey respondents in that study, $261(3.8 \%)$ were radiologists and $61 \%$ of the radiologists reported symptoms of burnout. Only $48 \%$ of radiologists had reported burnout in an earlier nationwide study conducted by the same authors in $2011(1,2)$. This disturbing trend of worsening burnout among radiologists was also reported in the Medscape Radiology Lifestyle report, in which the prevalence of burnout in practicing radiologists increased from 36\% in 2013 to $49 \%$ in 2017 (3). In order to address this growing problem, it is necessary to understand the risk factors that may potentially contribute to burnout in physicians.

\section{Increasing workload}

Numerous studies have reported that increasing workload is one of the leading sources of job related stress (25-29). Workloads in radiology have substantially increased in the last 20 years with the advent of PACS (Picture Archiving and Communications Systems), increased utilization of advanced cross sectional imaging with much larger sets of data to analyze, voice recognition software and self-editing, and an overall increase in the number of imaging studies read (30). Bhargavan et al. noted an increase of $70.3 \%$ annual work RVU's (relative value units) per FTE (full-time equivalent) radiologists from 1991-92 to 2006-07 (30). Other factors contributing to a sense of work overload include long work days with increased after hours responsibilities, greater expectations for report turnaround times, conflicting demands on time (clinical, academic, administrative), and inadequate staffing $(25,28)$. Studies also report that radiologists working a higher number of night shifts may be at a higher risk of burnout (31).

\section{Practice environment}

Current practice environments may also contribute to increasing levels of physician burnout. Studies suggest that $75 \%$ of all physicians are now employed by large organizations such as academic medical centers, health maintenance organizations, large practice groups and hospitals (32). Several authors have stated that an ineffective, outdated, and dominant hierarchical leadership paradigm may be a contributing source of burnout among radiologists $(28,32)$. An ascendant medical bureaucracy coupled with drives toward commoditization, market consolidation, and cost containment may contribute to low physician morale (28).

Working in a private practice setting has also been reported to be a potential contributory factor to radiologist burnout (26). Chew et al. reported a higher prevalence of emotional exhaustion, depersonalization, and lack of personal accomplishment in private practice radiologists compared to those in academic practice, although this difference was only statistically significant for emotional exhaustion (26). However, it has to be acknowledged that this study sample was small and limited to only a specific subspecialty of radiology (musculoskeletal radiologists) and hence larger studies are warranted.

The practice setting of an academic radiologist has its own unique contributory factors to radiologist burnout. There are a number of reasons one chooses to pursue a career in academics, including the opportunity to teach, perform research, work with expert subspecialist colleagues, and experience the complexity of cases seen at a tertiary referral 
center (33). Anything that impedes academic radiologists from accomplishing these goals act as stressors and may lead to burnout. The pressure to publish or obtaining external funding, difficulty/ delay in getting promoted to higher academic rank and having inadequate time to teach the trainees are important factors that can cause career dissatisfaction among academic radiologists, potentially contributing to burnout (33).

The stage of the physician career may also have a role to play in the incidence of burnout. Dyrbye et al. surveyed a large sample of US physicians from all specialties and found that middle career physicians (11-20 years) worked more hours, took more call, reported lowest specialty satisfaction, were more dissatisfied with work-life balance, and struggled more with emotional exhaustion and burnout than their early or late career colleagues (34). Although not specific to radiologists, a study on physician wellness at Stanford University reported that suboptimal compensation may result in professional dissatisfaction (35).

\section{Communication and Autonomy}

Poor communication is an additional driver of job dissatisfaction. Perceived lack of appreciation and recognition for one's work, lack of input and involvement in the decision making process, lack of support, and lack of transparency are important factors that may lead to discontent and potentially increase burnout symptoms (27).

Loss of professional autonomy can contribute to burnout. Lack of control over daily clinical schedule, on call responsibilities, work pattern and vacation schedule may lead to decreased satisfaction with work life balance, and thereby contribute to work-related stress $(28,32,34$ $37)$.

\section{Work Environment: PACS and Electronic Medical Record (EMR) and Isolation}

The advent of PACS and the electronic medical record (EMR) have improved the delivery of medical care in many ways, but has also contributed to the increasing isolation of the radiologist (38). Before PACS, regular face-to-face interactions between referring clinicians and clinical radiologists were common practice. As a result of these interactions, the radiologists developed a greater understanding of the clinical problem at hand, which in turn led to more meaningful and impactful radiology reports. Apart from improving patient care, such frequent interactions with other health care professionals also enhanced the radiologist's sense of belonging to the healthcare team and reinforced the critical role played by them in deciding optimal patient management. An unintended, unfortunate negative effect of PACS has been the substantial decrease in the face-to-face and telephone consultations between referring physicians and radiologists (38). This resultant increase in isolation of radiologists from other health care professionals may potentially contribute to a low sense of personal achievement and increased depersonalization $(29,32)$.

The sedentary and stationary aspect of radiology (39) and working in the dark may also adversely affect the radiologist's sense of wellbeing. Reduced sunlight and associated disruptions in circadian rhythm can cause seasonal affective disorder and may contribute to depression and burnout in professionals such as radiologists, who work in areas of low ambient light for prolonged periods of time (40). 


\section{Trainee Burnout}

High burnout rates have also been reported among radiology trainees. McNeeley et al. surveyed 266 radiology trainee members of the Association of University Radiologists and reported that over $50 \%$ of the radiology residents may be experiencing symptoms of emotional exhaustion and depersonalization (41). Interestingly, subjective self-assessments of financial strain were statistically significant predictors of depersonalization and emotional exhaustion symptoms. Furthermore, there was a statistically significant correlation between recent moonlighting activity and higher levels of personal achievement, lower emotional exhaustion, and greater quality of life. A more recent study published in 2017 reported similar findings of high burnout rate among radiology residents in New England (42). Increased residency year was shown to have statistically significant correlation with high emotional exhaustion as well as depersonalization (42).

\section{Interventions: What can be done to Reduce Burnout in Radiologists and Promote Health and Wellness?}

Burnout is a systemic issue (43-45), and reducing burnout is a shared responsibility of both health care organizations and individual physicians (Table 1) (27, 43, 46-51). Some possible solutions for radiologist burnout are summarized in the following categories: physiciandirected interventions \& organizational interventions.

\section{Physician-Directed Interventions}

Several authors have reported that an important aspect of preventing and treating burnout is "restoring lifestyle balance" within four domains: physical, emotional/spiritual, relationships and work-time off balances (27).

Physical balance includes optimization of overall health and appropriate physical activities. Obtaining adequate sleep, ensuring proper nutrition, participation in regular physical activity, and participation in extracurricular activities are useful strategies to combat feelings of burnout.

Taking care of one's emotional and social self is equally important (49). Emotional and spiritual balance could be assessed by journaling daily positive experiences as well as activities or thoughts that lead to a sense of well-being and accomplishment. Frequent selfassessment, acknowledging feelings of gratitude, and healthy spiritual practices may help to achieve optimum emotional and spiritual wellbeing (49).

Mindfulness as a coping mechanism for stress reduction has been extensively studied. A recent meta-analysis by Khouri et al. revealed that mindfulness-based stress reduction is moderately effective in reducing stress, depression, anxiety and distress (50). However, further research is warranted to identify the most effective elements of mindfulness-based stress reduction (50).

In some cases, a radiologist experiencing issues with burnout may need help from a mental health professional (27). In general, physicians are often reluctant to seek help from mental health services due to the stigma associated with it (52-54). Some institutions have 
developed novel ways to overcome this barrier such as intentionally combining financial planning with peer support services so that the stigma associated with accessing peer support is reduced (55)

Relationship balance is vital since a physician's well-being will affect not just themselves but also their loved ones. Long work shifts result in decreased time spent with family and friends. This reduces opportunities to form new relationships and decreases the physicians' ability to develop a significant support network $(27,56)$. Taking pro-active approach to ensure that adequate time is spent with loved ones may help to counter work related stress and reduce work-life conflict (56).

Achieving balance between work and time-off may help to reduce burnout $(27,49)$. Radiologists should not work for only financial reasons but also enjoy their profession and job. Having appropriate time off from work can help to relax and de-stress, and the rejuvenated physician may find work more enthusiastic and stimulating. Radiologists should also conduct self-appraisal to assess which aspect of their non-clinical professional work (teaching trainees, research, administration etc.) provides them high job satisfaction and try to spend more time on those activities. Finding meaning outside work may also help combat burnout. Indulging in leisure and volunteering activities outside of the workplace that are personally meaningful may promote the overall well-being $(27,49)$.

Various other strategies have also been proposed to help overcome physician burnout including cognitive behavioral therapies and improving physicians' self-confidence and communication skills $(47,57)$. Some authors have also reported that combining institutional group and individual interventions are more likely to be successful $(47,58,59)$. Facilitated and non-facilitated small group sessions may help improve meaning and engagement in work (59).

\section{Organization-Directed Interventions}

Organization-directed interventions have a significantly greater impact in addressing burnout compared to physician-directed interventions alone, supporting the fact that burnout is a systematic problem involving the entire health care organization and not just the individual physician (57).

The implementation of organization-directed strategies to promote physician well-being should begin with acknowledging and assessing the problem. The acknowledgement of physician burnout as a problem demonstrates that the organizational leadership cares about the well-being of its physicians, and is the necessary first step needed to make progress (60). Organization-directed interventions that combine elements such as structural changes to the organization, encouraging open communication between health care leadership and physicians, and cultivating a sense of teamwork and job control tend to be the most effective in reducing physician burnout (61).

Open Communication and Transparency from Leadership-Open communication and transparency between an organization and its staff is vital $(27,51,62)$, and can include open forum meetings, face-to-face meetings and interviews, a suggestion box system, 
surveys, a 24/7 physician telephone hotline, and letters (physical or electronic). Discussions regarding physician burnout should be encouraged between the two parties to build the trusting relationship needed to work together to improve physician well-being.

Measure and Address Wellness Routinely as an Organization-In addition to having an organizational method to discuss and acknowledge the problem, it is necessary to routinely quantify physician well-being to monitor for progress and change (63-65). The utilization of standardized tools with national data can be useful to provide a framework for interpreting results and making comparisons to the national trends (65-69). There are multiple quantifiable factors that contribute to physician well-being, including personal fulfillment, work engagement, stress, work-life balance, and quality of life. The raw data should be anonymous at the level of the individual; however, the aggregate data should be reported to the physicians and staff to promote self-awareness. The aggregate data can also be used to examine relationships with other measures of organizational performance, such as patient satisfaction scores, financial metrics, productivity (e.g., volume of radiologic studies dictated), and safety/quality.

Provide Workflow Autonomy-Having adequate staffing is important as this can help to share the workload appropriately, afford greater job flexibility and allow greater work-life balance (70). When case volume loads increase unexpectedly, groups can offer to pay a few members of the group to work extra hours rather than requiring all of the radiologists to work longer (27). Some groups have been able to hire full- or part-time radiologists for night and weekend shifts, further decreasing the stress on those who prefer to work those shifts less often. During busy periods, having shorter shifts and/or overlapping coverage may also be helpful to alleviate the workload (27). Another option is to allow radiologists to work longer hours on certain days of the week and shorter hours on other days to allow individuals to meet personal responsibilities without having to reduce total work effort. Groups should also examine their policies regarding vacation benefits and coverage for major life events, such as the birth of a child, death in the family, child's graduation, etc. Reimbursement practices that financially discourage the use of vacation time should be avoided. Organizations should also be supportive of individuals wanting to work part time $(56,71,72)$. If a radiologist makes the decision to work part-time, the culture of the group should support that provider as an equal and valued member of the group

\section{Encourage and Maintain Strong Leadership Style and Mentorship}

Opportunities_Physicians who consistently operate in a high-stress environment are 15 times more likely to develop burnout (73). When a radiologist starts a new job, an orientation that allows one to shadow a more senior radiologist and use him/her as a mentor can reduce stress. Additionally, having effective leaders in the department promotes the wellness of individual physicians, as well as the entire organization (74). Effective leaders know the strengths of their individual physicians, what motivates them, and how to best harness their talents. Physicians who spend up to $20 \%$ of their professional time focused on an aspect of work they find most meaningful are at a dramatically lower risk for burnout (75). Therefore, department/ divisional leadership should consider encouraging radiologists to become involved in professional activities that they are passionate about. These may 
include a wide range of activities such as undertaking administrative roles within the department or institution, spending more time on teaching trainees, involving in clinical or basic science research, developing community outreach programs, or serving in professional societies.. Effective leaders also represent their individual physicians at the hospital organizational level, and will speak on their behalf to ensure the alignment of department's work with the hospital's mission and values. This will help maintain facets of financial compensation, feasible expectations regarding turnaround time, and the practicality of other metrics hospital administration may want to incite on the department of radiology.

Electronic Medical Record and PACS support-Radiologists should be engaged in development, testing, optimization, and evaluation of any new EMR features such as clinical decision support, order sets, and templates. It is also important that radiologists receive advanced longitudinal training and support of new EMR features rather than limited onboarding training $(76,77)$. Clinicians should be responsible for only essential primary data entry that is required to support the care of a patient $(78,79)$. CMS (Centers for Medicare \& Medicaid Services) should also consider de-emphasizing documentation requirements (especially those that are clinically deemed irrelevant) as a condition of payment for healthcare services (78).

Create a Healthy and Collegial Work Environment-Reducing the isolation of the radiologist inside and outside of the reading room is another way to help prevent burnout. Fostering a culture of collegiality among radiologists and administrative staff in the work environment is a way to accomplish this. In particular, team huddles are increasingly being seen as a means not only to improve quality and workflow, but to increase communication and cooperation between and within teams (80). Specific approaches include eating lunch together or providing small tokens of encouragement at the workplace (e.g., celebrating holidays and staff birthdays and distributing certificates/rewards/gift cards for meeting certain metrics) $(51,80)$. Inter-departmental rounds or conferences give radiologists opportunities to directly interact with referring physicians. Ensuring opportunities for radiologists to get together outside of the workplace should also be encouraged.

Organizational Wellness Committee-Having a hospital organizational committee dedicated to physician wellness is key to acknowledging and addressing physician burnout and is gaining increasing popularity among health care organizations. These committees have multiple names such as a physician wellness committee or burnout prevention committee. However, the common goal is to actively survey and optimize physician wellness and satisfaction through targeted interventions (62). To ensure success, these committees should have the unwavering support of the organization's leadership (81). The committee should be made up of providers from varying specialties at different stages of professional career as well as administrators.

After analyzing data regarding the prevalence of burnout, the committee should develop targeted interventions based on the unique issues and suggestions received. Improvement of problems identified by radiologists, and all physicians alike, will improve physician satisfaction and provide the sense that their opinions are valued by the organization (82). 
The committee should then report back to the physicians and present the action items created to address specific issues, and the results of those interventions

Wellness and Burnout Resources provided by Organization-Organizations should also provide resources to make it easier for physicians to implement individual ways to prevent burnout, and to deal with difficult situations. The occurrence of frequent difficult situations (e.g., with patients, staff, colleagues, trainees, leadership) is associated with increased physician burnout and dissatisfaction. Resources to deal with difficult situations can include a listing of books or websites on coping strategies, a physician outreach program, a 24/7 physician hotline, or a regular scheduled opportunity to gather and discuss these issues (83). Opportunities should be provided to develop important non-medical skills that can help mitigate burnout. These skills include: team leadership, communication, stress management, problem solving, project management, quality improvement, and the basics of business and finance.

A recent article summarized the key organizational strategies that can help reduce professional burnout including designing organizational systems to address human needs, developing leaders with participative management competency, building social community, removing sources of frustration and inefficiency, reducing preventable patient harm, supporting health professionals involved in medical errors and bolstering individual wellness (51). Organizational interventions designed to promote greater employee control over work time and improve their work-life balance can help reduce psychological distress and increase job satisfaction (84). With a strong emphasis on organizational effectiveness, leadership interventions must focus on techniques and strategies that can positively frame change and increase overall productivity while maintaining and promoting physicians' wellbeing.

\section{Conclusion}

Burnout is pervasive among clinicians, and often goes under diagnosed and under reported. The incidence of burnout in health care professionals including radiologists is increasing at record levels. Urgent measures are needed to address this global malady. Several individual and organization-directed interventions have been discussed to help prevent burnout in radiologists and promote wellbeing. Preventing burnout in radiologists is vital for ensuring high physician satisfaction, optimal health care delivery and positive patient outcomes.

\section{Funding Acknowledgements:}

Dhakshinamoorthy Ganeshan was supported by P30 Cancer Center Support Grant No. NIH/NCI P30 CA016672 from the National Cancer Institute, National Institutes of Health

\section{References}

1. Shanafelt TD, Hasan O, Dyrbye LN, et al. Changes in Burnout and Satisfaction With Work-Life Balance in Physicians and the General US Working Population Between 2011 and 2014. Mayo Clin Proc 2015; 90(12):1600-13. [PubMed: 26653297]

2. Shanafelt TD, Boone S, Tan L, et al. Burnout and satisfaction with work-life balance among US physicians relative to the general US population. Arch Intern Med 2012; 172(18):1377-85.

[PubMed: 22911330] 
3. Peckham C "Medscape Radiologist Lifestyle Report 2017: Race and Ethnicity, Bias, and Burnout." http://www.medscape.com/features/slideshow/lifestyle/2017/radiology. Published 1 11, 2017 Accessed June 19, 2018

4. Aronsson G, Theorell T, Grape T, et al. A systematic review including meta-analysis of work environment and burnout symptoms. BMC Public Health 2017; 17(1):264. [PubMed: 28302088]

5. Elbarazi I, Loney T, Yousef S, Elias A. Prevalence of and factors associated with burnout among health care professionals in Arab countries: a systematic review. BMC Health Serv Res 2017; 17(1): 491. [PubMed: 28716142]

6. Lee RT, Seo B, Hladkyj S, Lovell BL, Schwartzmann L. Correlates of physician burnout across regions and specialties: a meta-analysis. Hum Resour Health 2013; 11:48. [PubMed: 24074053]

7. Pulcrano M, Evans SR, Sosin M. Quality of Life and Burnout Rates Across Surgical Specialties: A Systematic Review. JAMA Surg 2016; 151(10):970-8. [PubMed: 27410167]

8. Shanafelt TD, Gradishar WJ, Kosty M, et al. Burnout and career satisfaction among US oncologists. J Clin Oncol 2014; 32(7):678-86. [PubMed: 24470006]

9. Busireddy KR, Miller JA, Ellison K, Ren V, Qayyum R, Panda M. Efficacy of Interventions to Reduce Resident Physician Burnout: A Systematic Review. J Grad Med Educ 2017; 9(3):294-301. [PubMed: 28638506]

10. Baker K, Sen S. Healing Medicine's Future: Prioritizing Physician Trainee Mental Health. AMA J Ethics 2016; 18(6):604-13. [PubMed: 27322994]

11. Dyrbye L, Shanafelt T. A narrative review on burnout experienced by medical students and residents. Med Educ 2016; 50(1):132-49. [PubMed: 26695473]

12. Dyrbye LN, West CP, Satele D, et al. Burnout among U.S. medical students, residents, and early career physicians relative to the general U.S. population. Acad Med 2014; 89(3):443-51. [PubMed: 24448053]

13. Ishak W, Nikravesh R, Lederer S, Perry R, Ogunyemi D, Bernstein C. Burnout in medical students: a systematic review. Clin Teach 2013; 10(4):242-5. [PubMed: 23834570]

14. Thomas NK. Resident burnout. JAMA 2004; 292(23):2880-9. [PubMed: 15598920]

15. Dewa CS, Loong D, Bonato S, Trojanowski L. The relationship between physician burnout and quality of healthcare in terms of safety and acceptability: a systematic review. BMJ Open 2017; 7(6): 015141.

16. Salyers MP, Bonfils KA, Luther L, et al. The Relationship Between Professional Burnout and Quality and Safety in Healthcare: A Meta-Analysis. J Gen Intern Med 2017; 32(4):475-82. [PubMed: 27785668]

17. Hall LH, Johnson J, Watt I, Tsipa A, O’Connor DB. Healthcare Staff Wellbeing, Burnout, and Patient Safety: A Systematic Review. PLoS One 2016; 11(7):e0159015. [PubMed: 27391946]

18. Dewa CS, Loong D, Bonato S, Thanh NX, Jacobs P. How does burnout affect physician productivity? A systematic literature review. BMC Health Serv Res 2014; 14:325. [PubMed: 25066375]

19. Dyrbye LN, Shanafelt TD, Sinsky CA, Cipriano PF, Bhatt J, Ommaya A, West CP, and Meyers D 2017 Burnout among health care professionals: A call to explore and address this underrecognized threat to safe, high-quality care NAM Perspectives. Discussion Paper, National Academy of Medicine, Washington, DC https://nam.edu/Burnout-Among-Health-Care-Professionals.

20. Yaghmour NA, Brigham TP, Richter T, et al. Causes of Death of Residents in ACGME-Accredited Programs 2000 Through 2014: Implications for the Learning Environment. Acad Med 2017; 92(7): 976-83. [PubMed: 28514230]

21. Dyrbye LN, Thomas MR, Massie FS, et al. Burnout and suicidal ideation among U.S. medical students. Ann Intern Med 2008; 149(5):334-41. [PubMed: 18765703]

22. Center C, Davis M, Detre T, et al. Confronting depression and suicide in physicians: a consensus statement. JAMA 2003; 289(23):3161-6. [PubMed: 12813122]

23. Rothenberger DA. Physician Burnout and Well-Being: A Systematic Review and Framework for Action. Dis Colon Rectum 2017; 60(6):567-76. [PubMed: 28481850]

24. Maslach C, Schaufeli WB, Leiter MP. Job burnout. Annu Rev Psychol 2001; 52:397-422. [PubMed: 11148311] 
25. Graham J, Ramirez AJ, Field S, Richards MA. Job stress and satisfaction among clinical radiologists. Clin Radiol 2000; 55(3):182-5; discussion 6. [PubMed: 10708609]

26. Chew FS, Mulcahy MJ, Porrino JA, Mulcahy H, Relyea-Chew A. Prevalence of burnout among musculoskeletal radiologists. Skeletal Radiol 2017; 46(4):497-506. [PubMed: 28154900]

27. Harolds JA, Parikh JR, Bluth EI, Dutton SC, Recht MP. Burnout of Radiologists: Frequency, Risk Factors, and Remedies: A Report of the ACR Commission on Human Resources. J Am Coll Radiol 2016; 13(4):411-6. [PubMed: 26768546]

28. Nicola R, McNeeley MF, Bhargava P. Burnout in Radiology. Curr Probl Diagn Radiol 2015; 44(5): 389-90. [PubMed: 26025882]

29. Magnavita N, Fileni A, Magnavita G, et al. Work stress in radiologists. A pilot study. Radiol Med 2008; 113(3):329-46. [PubMed: 18493771]

30. Bhargavan M, Kaye AH, Forman HP, Sunshine JH. Workload of radiologists in United States in 2006-2007 and trends since 1991-1992. Radiology 2009; 252(2):458-67. [PubMed: 19508987]

31. Hanna TN, Shekhani H, Lamoureux C, et al. Emergency Radiology Practice Patterns: Shifts, Schedules, and Job Satisfaction. J Am Coll Radiol 2017; 14(3):345-52. [PubMed: 27927590]

32. Restauri N, Flug JA, McArthur TA. A Picture of Burnout: Case Studies and Solutions Toward Improving Radiologists' Well-being. Curr Probl Diagn Radiol 2017; 46(5):365-8. [PubMed: 28238370]

33. Kelly AM, Cronin P, Dunnick NR. Junior faculty satisfaction in a large academic radiology department. Acad Radiol 2007; 14(4):445-54. [PubMed: 17368214]

34. Dyrbye LN, Varkey P, Boone SL, Satele DV, Sloan JA, Shanafelt TD. Physician satisfaction and burnout at different career stages. Mayo Clin Proc 2013; 88(12):1358-67. [PubMed: 24290109]

35. Schrijver I, Brady KJ, Trockel M. An exploration of key issues and potential solutions that impact physician wellbeing and professional fulfillment at an academic center. PeerJ 2016; 4:e1783. [PubMed: 26989621]

36. Shanafelt TD, Mungo M, Schmitgen J, et al. Longitudinal Study Evaluating the Association Between Physician Burnout and Changes in Professional Work Effort. Mayo Clin Proc 2016; 91(4):422-31. [PubMed: 27046522]

37. Shanafelt TD, West CP, Sloan JA, et al. Career fit and burnout among academic faculty. Arch Intern Med 2009; 169(10):990-5. [PubMed: 19468093]

38. Hayt DB, Alexander S. The pros and cons of implementing PACS and speech recognition systems. J Digit Imaging 2001; 14(3):149-57.

39. Seidel RL, Krupinski EA. The Agony of It All: Musculoskeletal Discomfort in the Reading Room. J Am Coll Radiol 2017; 14(12):1620-5. [PubMed: 28899700]

40. Bender CE, Parikh JR, Arleo EK, Bluth E. The Radiologist and Depression. J Am Coll Radiol 2016; 13(7):863-7. [PubMed: 27085789]

41. McNeeley MF, Perez FA, Chew FS. The emotional wellness of radiology trainees: prevalence and predictors of burnout. Acad Radiol 2013; 20(5):647-55. [PubMed: 23570939]

42. Guenette JP, Smith SE. Burnout: Prevalence and Associated Factors Among Radiology Residents in New England With Comparison Against United States Resident Physicians in Other Specialties. AJR Am J Roentgenol 2017; 209(1):136-41. [PubMed: 28639920]

43. Williams ES, Konrad TR, Linzer M, et al. Physician, practice, and patient characteristics related to primary care physician physical and mental health: results from the Physician Worklife Study. Health services research 2002; 37(1):119.

44. Maslach C, Leiter MP. Understanding the burnout experience: recent research and its implications for psychiatry. World Psychiatry 2016; 15(2):103-11. [PubMed: 27265691]

45. Rees, L; [Accessed June 19, 2018] 8 things that can put you at risk of burnout. Available at: https:// wire.ama-assn.org/practice-management/8-things-can-put-you-risk-burnout.

46. Shanafelt TD, Sloan JA, Habermann TM. The well-being of physicians. The American journal of medicine 2003; 114(6):513-9. [PubMed: 12727590]

47. West CP, Dyrbye LN, Erwin PJ, Shanafelt TD. Interventions to prevent and reduce physician burnout: a systematic review and meta-analysis. The Lancet 2016; 388(10057):2272-81. 
48. [Accessed June 19, 2018] How to beat burnout: 7 signs physicians should know. Available at: https://wire.ama-assn.org/life-career/how-beat-burnout-7-signs-physicians-should-know.

49. Improving physician resiliency. [Accessed June 19, 2018] AMA Stepsforward. Available at: https://www.stepsforward.org/modules/improving-physician-resilience.

50. Khoury B, Sharma M, Rush SE, Fournier C. Mindfulness-based stress reduction for healthy individuals: a meta-analysis. Journal of Psychosomatic Research 2015; 78(6):519-28. [PubMed: 25818837]

51. Swensen SJ, Shanafelt T. An Organizational Framework to Reduce Professional Burnout and Bring Back Joy in Practice. Jt Comm J Qual Patient Saf 2017; 43(6):308-13. [PubMed: 28528625]

52. Gold KJ, Shih ER, Goldman EB, Schwenk TL. Do US Medical Licensing Applications Treat Mental and Physical Illness Equivalently? Fam Med 2017; 49(6):464-7. [PubMed: 28633174]

53. Gold KJ, Andrew LB, Goldman EB, Schwenk TL. "I would never want to have a mental health diagnosis on my record": A survey of female physicians on mental health diagnosis, treatment, and reporting. Gen Hosp Psychiatry 2016; 43:51-7. [PubMed: 27796258]

54. Dyrbye LN, West CP, Sinsky CA, Goeders LE, Satele DV, Shanafelt TD. Medical Licensure Questions and Physician Reluctance to Seek Care for Mental Health Conditions. Mayo Clin Proc 2017; 92(10):1486-93. [PubMed: 28982484]

55. Shanafelt TD, Lightner DJ, Conley CR, et al. An Organization Model to Assist Individual Physicians, Scientists, and Senior Health Care Administrators With Personal and Professional Needs. Mayo Clinic Proceedings: Elsevier; 2017; 1688-96.

56. Dyrbye LN, Sotile W, Boone S, et al. A survey of U.S. physicians and their partners regarding the impact of work-home conflict. J Gen Intern Med 2014; 29(1):155-61. [PubMed: 24043567]

57. Panagioti M, Panagopoulou E, Bower $P$, et al. Controlled interventions to reduce burnout in physicians: a systematic review and meta-analysis. Jama internal medicine 2017; 177(2):195-205. [PubMed: 27918798]

58. Morse G, Salyers MP, Rollins AL, Monroe-DeVita M, Pfahler C. Burnout in Mental Health Services: A Review of the Problem and Its Remediation. Administration and Policy in Mental Health and Mental Health Services Research 2012; 39(5):341-52. [PubMed: 21533847]

59. West CP, Dyrbye LN, Rabatin JT, et al. Intervention to promote physician well-being, job satisfaction, and professionalism: A randomized clinical trial. JAMA Internal Medicine 2014; 174(4):527-33. [PubMed: 24515493]

60. Shanafelt TD, Noseworthy JH. Executive leadership and physician well-being: nine organizational strategies to promote engagement and reduce burnout. Mayo Clinic Proceedings: Elsevier; 2017; 129-46.

61. Linzer M, Poplau S, Grossman E, et al. A cluster randomized trial of interventions to improve work conditions and clinician burnout in primary care: results from the Healthy Work Place (HWP) study. Journal of general internal medicine 2015; 30(8):1105-11. [PubMed: 25724571]

62. Mark Linzer MD FACP LG-CM, Poplau. Sara Preventing Physician Burnout Available at: https:// www.stepsforward.org/modules/physician-burnout. Accessed June 19, 2018.

63. Wallace JE, Lemaire JB, Ghali WA. Physician wellness: a missing quality indicator. The Lancet 2009; 374(9702):1714-21.

64. Spinelli WM. The phantom limb of the triple aim. Mayo Clinic Proceedings: Elsevier; 2013; 13567.

65. Shanafelt TD, Boone S, Tan L, et al. Burnout and satisfaction with work-life balance among US physicians relative to the general US population. Archives of internal medicine 2012; 172(18): 1377-85. [PubMed: 22911330]

66. Shanafelt TD, Hasan O, Dyrbye LN, et al. Changes in burnout and satisfaction with work-life balance in physicians and the general US working population between 2011 and 2014. Mayo Clinic Proceedings: Elsevier; 2015; 1600-13.

67. Williams ES, Konrad TR, Linzer M, et al. Refining the measurement of physician job satisfaction: results from the Physician Worklife Survey. Medical care 1999:1140-54. [PubMed: 10549616]

68. Dyrbye LN, Satele D, Sloan J, Shanafelt TD. Utility of a brief screening tool to identify physicians in distress. Journal of general internal medicine 2013; 28(3):421-7. [PubMed: 23129161] 
69. Dyrbye LN, Satele D, Shanafelt T. Ability of a 9-item well-being index to identify distress and stratify quality of life in US workers. Journal of occupational and environmental medicine 2016; 58(8):810-7. [PubMed: 27294444]

70. Bonner L Radiologists are burning out. Diagnostic Imaging 6 4, 2015.

71. Bluth EI, Bansal S. The 2016 ACR Commission on human resources workforce survey. Journal of the American College of Radiology 2016; 13(10):1227-32. [PubMed: 27497522]

72. Dyrbye LN, Shanafelt TD, Balch CM, Satele D, Sloan J, Freischlag J. Relationship between workhome conflicts and burnout among American surgeons: a comparison by sex. Archives of surgery 2011; 146(2):211-7. [PubMed: 21339435]

73. How to beat burnout: 7 signs physicians should know. AMA Wire: Life and Career Available at: https://wire.ama-assn.org/life-career/how-beat-burnout-7-signs-physicians-should-know. Accessed June 19, 2018

74. Shanafelt TD, Gorringe G, Menaker R, et al. Impact of organizational leadership on physician burnout and satisfaction. Mayo Clinic Proceedings: Elsevier; 2015; 432-40.

75. Shanafelt TD, West CP, Sloan JA, et al. Career fit and burnout among academic faculty. Archives of Internal Medicine 2009; 169(10):990-5. [PubMed: 19468093]

76. Kim JG, Rodriguez HP, Estlin KA, Morris CG. Impact of Longitudinal Electronic Health Record Training for Residents Preparing for Practice in Patient-Centered Medical Homes. The Permanente journal 2017; 21.

77. ANDERSON M The impact of university provided nurse electronic medical record training on health care organizations: An exploratory simulation approach. Driving Quality in Informatics: Fulfilling the Promise 2015; 208:1.

78. Ommaya AK, Cipriano PF, David B, et al. Care-Centered Clinical Documentation in the Digital Environment: Solutions to Alleviate Burnout 2018.

79. Friedberg MW, Chen PG, Van Busum KR, et al. Factors affecting physician professional satisfaction and their implications for patient care, health systems, and health policy. Rand health quarterly 2014; 3(4).

80. Cracknell A LA, Winfield A, Arkhipkina S, McDonagh E, Green A, Rooney M. Huddle up for safer healthcare: how frontline teams can work together to improve patient safety. Future Healthcare J 2016;3(2):s31.

81. Drummond, D; [Accessed September 20, 2017.] Balancing Responsibility for Physician Wellness and Engagement: 117 Ways Doctors and Healthcare Organization can Lower Stress and Prevent Burnout. Available at: https://support.thehappymd.com/physician-burnout-prevention-matrix.

82. Snipes RL, Loughman T, Fleck RA. The effects of physicians' feelings of empowerment and service quality perceptions on hospital recommendations. The Quality Management Journal 2010; 17(4):51.

83. An PG, Rabatin JS, Manwell LB, Linzer M, Brown RL, Schwartz MD. Burden of difficult encounters in primary care: data from the minimizing error, maximizing outcomes study. Archives of Internal Medicine 2009; 169(4):410-4. [PubMed: 19237726]

84. Moen P, Kelly EL, Fan W, et al. Does a flexibility/support organizational initiative improve hightech employees' well-being? Evidence from the work, family, and health network. American Sociological Review 2016; 81(1):134-64. 
Table 1.

Potential risk factors that may contribute to burnout and various physician and organization-directed interventions to overcome burnout $(27,43,46-51)$.

\begin{tabular}{|c|c|}
\hline Risk factors that may contribute to physician burnout & Interventions to overcome burnout \\
\hline $\begin{array}{l}\text { Excessive workload } \\
\text { Long work hours, high number of night calls/ overnight shifts } \\
\text { Imbalance between job demands and skills } \\
\text { Loss of professional autonomy } \\
\text { medical error } \\
\text { Being midway through professional career } \\
\text { means than } 20 \text { percent of a physician's time is spent on the most } \\
\text { Suboptimal financial compensation } \\
\text { Physicians whose spouse/ partner are also a physician } \\
\text { Work-home conflict } \\
\text { Lack of adequate EMR and PACS support } \\
\text { Lack of appreciation and recognition for one's work } \\
\text { Lack of input and involvement in the decision making process } \\
\text { Poor communication from leadership } \\
\text { Isolation of radiologists from other health care professionals }\end{array}$ & $\begin{array}{l}\text { A) Physician-Directed Interventions } \\
\text { Restoring physical balance, emotional/ spiritual balance, } \\
\text { relationships balance, work-time off balances } \\
\text { Mindfulness } \\
\text { Cognitive behavioral therapies } \\
\text { Provide and encourage seeking professional help from mental } \\
\text { health services } \\
\text { Educational strategies for improving physicians' self- } \\
\text { confidence and communication skills } \\
\text { Facilitated and non-facilitated small group sessions } \\
\text { B) Organization-Directed Interventions } \\
\text { Open Communication and Transparency from Leadership } \\
\text { Measure and Address Wellness Routinely as an Organization } \\
\text { Provide Workflow Autonomy } \\
\text { Mentorship Opportunities } \\
\text { EMR and PACS support } \\
\text { Create a Healthy and Collegial Work Environment (team } \\
\text { huddles) } \\
\text { Organizational Wellness Committee } \\
\text { Wellness and Burnout Resources provided by Organization }\end{array}$ \\
\hline
\end{tabular}

